\title{
Sports Injury and Illness Epidemiology: Thailand Team Surveillance During the 30th Southeast Asian Games
}

\author{
Kotchakorn Jumroenketpratheep ${ }^{1}$, Htet Zayar (iD) ${ }^{1}$, Kittinad Kaewkul ${ }^{2}$ and Kornkit Chaijenkij ${ }^{1, *}$ \\ ${ }^{1}$ Sports Medicine Center, College of Sports Science and Technology, Mahidol University, Salaya, Thailand \\ ${ }^{2}$ General Education, Siam Technology College, Thailand \\ "Corresponding author: Sports Medicine Center, College of Sports Science and Technology, Mahidol University, Salaya, Thailand. Email: kornkit.cha@mahidol.edu
}

Received 2021 May 23; Revised 2021 September 28; Accepted 2021 December 24.

\begin{abstract}
Background: Injury and illness surveillance in sports is the first step of the injury prevention model that generates effective injury prevention measures.

Objectives: To identify the incidence, severity, and causes of injuries and illness in the Thailand national team during the 30 th Southeast Asian (SEA) Games.

Methods: All medical encounters were documented using the International Olympic Committee (IOC) injury and illness surveillance system for multi-sport events. We recorded the daily occurrence of injuries and illnesses reported by Thailand's medical teams over the 12 days of the competition period.

Results: Among 980 Thai athletes (568 male and 412 female), that participated in the 30th SEA Games, a total of 105 injuries and illnesses were reported. There were 84 injuries and 21 illnesses which equated to an incidence of 86 injuries and 21 illnesses per 1000 athletes. The most commonly injured body part was the lower leg (14\% of all injuries), followed by the shoulder and clavicle. Ligament sprain or rupture and contusion (25\% of all injuries) were reported as the most common type of injury. Of all injuries, 56 were classified as needing medical attention (only), 26 caused performance restriction, and two caused complete-time loss. The most common athlete illness was respiratory illness (48\% of all illnesses) followed by gastrointestinal illness (19\% of all illnesses). One-third (7 out of 21) of athlete illnesses restricted the athlete's performance, and the remaining 14 only required medical attention. Conclusions: Overall, $8 \%$ of athletes incurred at least one injury during the competition, and $2 \%$ suffered from an illness. Lower leg injury and respiratory illness were the most common, which is similar to other multi-sport events. Based on the research data, injury prevention, especially of ligamentous sprain and lower limb injuries, should be the focus in multi-sport events.
\end{abstract}

Keywords: Epidemiologic Studies, Athletic Injuries, Surveillance

\section{Background}

The ever-increasing demand to win sports tournaments can cause athletes to become more stressed and more prone to injury, even though sports and physical activities can be an important part of a healthy lifestyle (1, 2). Therefore, the International Olympic Committee (IOC) and sports federations take an interest in injury and illness prevention with the intention of protecting the athletes' health (3). Epidemiological data will help with the planning and implementation of athlete healthcare, and the development of injury and illness prevention methods (4). It can assist in identifying characteristics of illness and injury, as well as provide insight into different methods and procedures being used to minimize the risk of illness and injury $(5,6)$. Therefore, the injury and illness surveillance procedure is a matter of concern to protect the athletes' health and to identify epidemiological information that can yield preventive measures $(7,8)$.

Injury surveillance is the first step of the injury prevention model (9). Some sports authorities or the International Sports Federations have applied the injury and illness surveillance system either longitudinally, over one or more seasons, or in a certain main event (4). During the 2014 Winter Olympics in Sochi, it was reported that the injury rate was twice as high as the illness rate in the Great Britain team (10). A previous study suggested that injury surveillance, using the electronic health records (EHR) systems, could lead to better integration of medical data. It could also assist the advancement of basic epidemiologic research for risk factor identification and injury and disease prevention (11). When it comes to injuries, lower limbs have been the most common, and sprain injuries have also been found commonly in multi-sport events $(3,4,12)$. As 
with multi-sports events, respiratory tract infections were the most prevalent illness encountered $(3,4)$.

For these reasons, the Sports Authority of Thailand planned to apply the injury and illness surveillance system in the Thailand national team during the Philippine 2019 South East Asian (SEA) Games. The South-East Asian (SEA) Games are the most popular and most significant multi-sport event in South East Asian countries. In the 30th SEA Games, a total of 5,630 athletes from eleven Southeast Asian countries participated. The games included 530 events in 56 sports. As far as we know, there have been no previous injury and illness surveillance studies for Thailand's team in previous SEA Games.

\section{Objectives}

This was the first injury and illness surveillance for the Thailand national team in multi-sports events. Its aim was to investigate the incidence, severity, and mechanism of sports injury and illness during the 2019 (30th) SEA Games.

\section{Methods}

The 30th SEA Games was hosted at four clusters which are all located on the island of Luzon, Philippines, between November 30 and December 11,2019. During the games, the average temperature was 26 degrees Celsius (range 21 to 30 degrees Celsius) with a humidity of approximately $77 \%$. In addition, 14 outdoor sports competitions were rescheduled during the 30th SEA Games due to Typhoon Kammuri. 980 athletes $(17.4 \%$ of the total athletes of the 30th SEA Games) from the Thailand team participated in the 30th SEA Games, and all Thailand national team athletes participated in this prospective cohort study. Study procedures were approved by the central institutional review board of Mahidol University (COA No. MU-CIRB 2019/194.0811).

In this 12-day-long observational prospective cohort study, all medical encounters were recorded using the International Olympic Committee (IOC) injury and illness surveillance system for multi-sport events. We introduced and explained the IOC injury and illness system to every medical team member of the Thailand team one week before the competition. In addition, we provided either an electronic reporting form or a standardized manual report form to report the daily occurrence of athletes' injuries and illnesses during the 2019 SEA Games. We then created an electronic report form using Google Forms based on the IOC injury and illness format (13). Two researchers collected these data and reminded the team physician and medical staff to report injuries and illnesses on a daily basis. We used the athlete's accreditation number to control duplicates because there were two options to report (ie, an online form and a manual record form).

\subsection{Definition of Injury and Illness}

We characterized injuries and illnesses as new (ie, preexisting injuries in which the athlete had not fully recovered were not included) or recurring (athletes who returned to full participation after an injury or illness) musculoskeletal complaints, concussions, or other medical conditions (injuries) or illnesses that occurred during the competition or training for the 30th SEA Games $(4,6)$. In some cases where a single incident caused multiple injury types or affected multiple body parts, only the most severe diagnosis was recorded $(3,4,10)$. Severe injuries and illnesses were defined as those that required an absence from training or competition for more than one week. Timeloss was defined as performance restriction not over seven days, and medical attention was defined as an injury or illness that did not interfere with the athletes' training or competition.

\subsection{Data Analysis}

The summary measures of injury and illness incidence have been calculated according to the formula $\mathrm{I}=\mathrm{n} / \mathrm{e}$, where $\mathrm{n}$ is the number of injuries or illnesses in competition, training, or in total during the study period and e is the respective number of exposed athletes. Incidence values are presented as injuries/illnesses per 1000 athletes. This method was consistent with previous research (10, 14) that evaluated an injury and illness in major sporting events. The injury and illness incidence was presented as mean and RRs with 95\% CIs. For all statistical analysis, the current study used IBM SPSS Statistics Software, version 23.0 (IBM Corp., Armonk, NY, USA).

\section{Results}

\subsection{Number and Severity of Injuries and Illnesses}

A total of 980 Thailand athletes participated in the 30 th Philippine SEA Games. Of these, 568 were men (58\%) and 412 women (42\%). Throughout the 12 days of the 30th SEA Games, there were 84 injuries and 21 illnesses recorded within the Thailand team. This equated to an incidence of 86 injuries and 21 illnesses per 1000 athletes. Considering all injuries, 56 were classified as requiring medical attention only, 26 causing time loss (ie, performance restriction not over seven days), and two caused severe injuries (ie, performance restriction over seven days) (Table 1). The two severe injuries were discovered in a floorball player due to contact with another athlete and a judo player due to recurrence of an anterior cruciate ligament (ACL) injury 
while training for the games. For athlete illnesses, seven out of 21 were performance restrictions, and the rest were classified as needing medical attention only (Table 1 ).

\subsection{Rate of Injuries and Illnesses}

The majority of injuries (56 injuries or 66.7\%) occurred during competition, and the majority of illnesses (16 illnesses or $76.2 \%$ ) occurred during training. The odds ratio (OR) was 0.16 (95\% CI: 0.05 to $0.47 ; \mathrm{P}=0.00)$. The prevalence of injury in males was $10 \%$ ( 57 injuries of a total of 568 male athletes) and 6.6\% in female athletes (27 of a total 412 female athletes). The odds ratio (OR) was 1.6 (95\% CI: 0.99 to $2.6 ; \mathrm{P}=0.06)$. The prevalence of illness in males was $3.3 \%$ (17 out of a total of 568 male athletes) and $1 \%$ in females (4 out of a total 412 female athletes). The odds ratio (OR) was 3.1 (95\% CI: 1.0 to $9.4 ; \mathrm{P}=0.03$ ).

\subsection{Characteristics of Injury}

The most common injuries based on anatomical location were injuries to the lower leg (14\% of all injuries), followed by injuries to the shoulder and clavicle. In addition, injuries to the thigh, knee, and ankle, were recorded as being the most commonly injured body part for the Thailand team (Figure 1). Sprains (injury of joints/ligaments; 25\%) and contusions (25\%) were the most common types of injury, followed by muscle cramps or spasms (7.1\%). The most common cause of injury was contact with another athlete (37\% of total injury), followed by overuse (gradual/sudden onset; $26 \%$ ).

\subsection{Nature of Illness}

The most common athlete illness was respiratory illness within the Thailand team during the 30th SEA Games, causing $48 \%$ of all illnesses. This was followed by gastrointestinal illness (19\%). The most common causes of athlete illness were infection and environment (33\%), with dyspnea and cough (33\%) being the most commonly reported symptoms.

\section{Discussion}

The injury and illness surveillance system is the first step for injury prevention in the field of sports medicine $(5,15)$. Early detection, evaluation of the acuity or chronicity of the injury, and treatment (16) are considered crucial roles in reducing the risk of injuries in sports. The predominant findings of this study were: (1) the number of injuries was approximately four times the number of athletes' illnesses, (2) the lower limb, including knee, thigh, and ankle, was the most commonly injured body part, (3) contact followed by overuse (sudden/gradual onset) were the most common causes of injury and (4) the most common illness was related to the upper respiratory tract. Hopefully, these findings will enable sports management agencies to improve athletic performance during competitive games.

The overall incidence of injury in the present study was 86 injuries and 21 illnesses per 1000 athletes, respectively. This was lower than previously published injury and illness reports. For example, there were 128.8 injuries and 71.7 illnesses per 1000 athletes in the 2012 Olympics, as well as 98 injuries and 54 illnesses per 1000 athletes in the 2016 Olympics (Table 2) $(3,4)$. Moreover, the incidence of injury and illness in this study was lower than that reported by Team Great Britain and Team USA in the Olympics and also lower than that reported by Team Malaysia in the Asian Games (Table 2) $(10,11,17)$. However, when making a comparison of our data to others, team USA medical staff documented every medical encounter, including basic wound care during competition (11). Yet, in our study, recorded injuries and illnesses were only those which required a higher level of medical attention. In addition, the ratio of the athletes per practitioner on the Thailand team (23 athletes per practitioner) was higher than the ratio of the athletes per practitioner on the Great Britain team ( 6 athletes per practitioner) (10). Therefore, the incidence of injury and illness was highly dependent on the response rate and the ratio of medical staff to athletes (11). This fact could elucidate our low incidence of injury and illness rate in Thai athletes during the 30th SEA Games.

The lower limb (ankle, thigh, and knee) was the most commonly injured body part, and ligament sprain is the most common cause of injury in multi-sports events (Table $2)(3,4)$. Most of the injuries occur in taekwondo, football, handball, bicycle motocross (BMX), and hockey $(3,4)$. Similar to previous reports, our study demonstrated that lower limb injury and ligament sprain or rupture were the most common injuries in Thai athletes in the 30th SEA Games. These injuries happened most often in football and floorball, which mainly use their lower limbs in order to sprint, jump, and land. These findings imply that the more the lower limb is used, the higher the probability of injury. Thus, lower limb ligament sprain or rupture should be an essential issue for sports injury prevention for every athlete, coach, and medical practitioner. The proper implementation of a training program, with special focus on the athletes' lower limb $(17,18)$, could be vital for athletes to improve the outcome of their competitions.

When it comes to mechanism of injury, the most common causes of injury in this study were contact with other athletes followed by overuse (sudden/gradual start). This is consistent with previous studies from the London and Rio Olympics (Table 2) where contact with another athlete and overuse (sudden/gradual onset) were the most common 
Jumroenketpratheep Ket al.

\begin{tabular}{|c|c|c|c|c|c|c|c|}
\hline \multirow{2}{*}{\multicolumn{2}{|c|}{ Sport }} & \multicolumn{3}{|c|}{ Injury } & \multicolumn{3}{|c|}{ Illness } \\
\hline & & Medical Attention & Time-loss & Severe Injury & Medical Attention & Time-loss & Severe Illness \\
\hline \multicolumn{8}{|c|}{ Contact } \\
\hline & Floorball & 4 & 2 & 1 & 1 & 2 & 0 \\
\hline & Football & 9 & 4 & 0 & 1 & 1 & 0 \\
\hline & Handball & 1 & 0 & 0 & 0 & 0 & 0 \\
\hline & Hockey & 4 & 1 & 0 & 2 & 0 & 0 \\
\hline & Ice hockey & 0 & 1 & 0 & 0 & 0 & 0 \\
\hline & Judo & 1 & 4 & 1 & 0 & 0 & 0 \\
\hline & Karate & 2 & 0 & 0 & 0 & 0 & 0 \\
\hline & Muay Thai & 5 & 0 & 0 & 0 & 0 & 0 \\
\hline & Netball & 1 & 0 & 0 & 0 & 0 & 0 \\
\hline & Pencak silat & 5 & 0 & 0 & 0 & 0 & 0 \\
\hline & Sambo & 0 & 1 & 0 & 1 & 0 & 0 \\
\hline & Wrestling & 0 & 2 & 0 & 0 & 0 & 0 \\
\hline & Wushu & 2 & 0 & 0 & 0 & 0 & 0 \\
\hline & Baseball & 0 & 1 & 0 & 0 & 0 & 0 \\
\hline & Beach handball & 3 & 0 & 0 & 0 & 1 & 0 \\
\hline \multicolumn{8}{|c|}{ Non-contact } \\
\hline & Athletic & 1 & 1 & 0 & 1 & 1 & 0 \\
\hline & Badminton & 0 & 1 & 0 & 0 & 0 & 0 \\
\hline & Canoe & 2 & 0 & 0 & 0 & 0 & 0 \\
\hline & Chess & 3 & 0 & 0 & 0 & 0 & 0 \\
\hline & Duathlon & 0 & 1 & 0 & 0 & 1 & 0 \\
\hline & Gymnastics & 3 & 0 & 0 & 0 & 0 & 0 \\
\hline & Marathon & 0 & 1 & 0 & 0 & 0 & 0 \\
\hline & Rowing & 1 & 0 & 0 & 0 & 0 & 0 \\
\hline & Running & 2 & 4 & 0 & 7 & 0 & 0 \\
\hline & Sailboat & 1 & 0 & 0 & 0 & 0 & 0 \\
\hline & Sepak takraw & 3 & 0 & 0 & 0 & 0 & 0 \\
\hline & Shooting & 0 & 0 & 0 & 1 & 0 & 0 \\
\hline & Skateboard & 0 & 1 & 0 & 0 & 0 & 0 \\
\hline & Windsurf & 3 & 1 & 0 & 0 & 1 & 0 \\
\hline Total & & 56 & 26 & 2 & 14 & 7 & 0 \\
\hline
\end{tabular}

causes of injury $(3,4)$. To prevent contact sport injuries, protective interventions should be introduced, including: (1) wearing protective gear, (2) doing warm-ups and cooldowns, (3) education regarding the rules of the games and possibility of injury, and (4) awareness of the opponent's playing behavior (18). Concerning overuse injuries, these are difficult to diagnose; however, a questionnaire such as the Oslo Sports Trauma Research Centre (OSTRC) overuse injury questionnaire should be used to evaluate and longitudinally monitor an athlete's health status. This questionnaire could help healthcare practitioners to identify early stages of overuse injury in athletes during training (19). Consequently, overuse injuries could be avoided by increased monitoring of athletes' training regimen and their personal health.

Turning from injuries to illness, during the 30th SEA Games, respiratory illness was found to be the most common illness for the Thailand team. Infection and environ- mental factors were the most common cause of illness during this competition. Previous studies also reported respiratory illness as being commonplace, as evident in reports about Team Great Britain, Team USA, and Team Malaysia in previous surveillance studies (Table 2$)(10,11,17)$. In addition, infection and environmental factors were also the major contributory factors to illness from The Olympic Games in London and Rio (3, 4). Several immune system components appear to be reduced after prolonged endurance exercise or during intense exercise training. As a result, a weakened immune system tended to increase the risk of upper respiratory tract infection (20). In contrast, good personal hygiene, avoiding high load activities whilst suffering from a systemic illness, and proper immunization before competition can reduce the risk of illness $(20,21)$. Thus, prevention of respiratory tract infection during competition by focusing on the immune system as well as hygiene status should be carefully monitored in future 


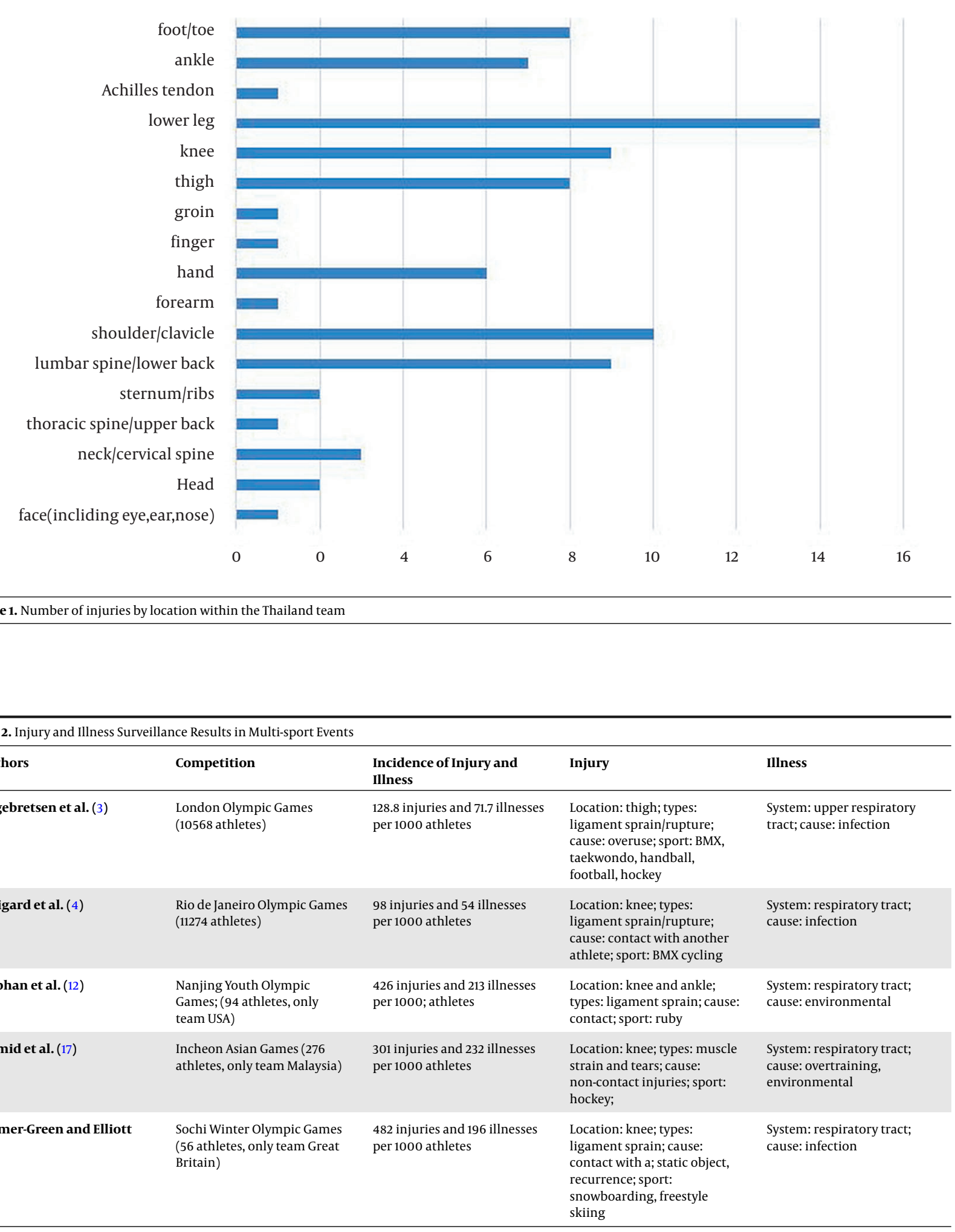


studies in order to help reduce the incidence of illness in future multi-sports events.

\subsection{Conclusions}

Injury and illness surveillance is the first step of the injury prevention model. From it, we can glean a lot of information. Our study confirms that the lower limb is the main site of injury in competitive sports. Contact with other athletes during competition as well as overuse during training are the most common causes of lower limb injury during competition. In addition, respiratory illness is quite common among competitive athletes. Hopefully, these important facts can be used to develop protective measures that will help prevent injury and illness in multisport events. Future initiatives should include the development of preventive measures targeted for lower limb injury and respiratory illness.

\subsection{Limitation of the Study}

This study investigated injury and illness occurrences only for the Thailand team during the 30th SEA Games. Furthermore, the method of data collection does not describe in detail risk factors of injury or illness, such as demographic, anthropometric, athletic exposure, health history, and training history.

\section{Footnotes}

Authors' Contribution: Study concept and design: K. Chaijenkij, and K. Jumroenketpratheep; Analysis and interpretation of data: K. Chaijenkij, K. Jumroenketpratheep, and H. Zayar; Drafting of the manuscript: K. Chaijenkij, K. Jumroenketpratheep, and $\mathrm{H}$. Zayar; Critical revision of the manuscript for important intellectual content: K. Jumroenketpratheep, K. Chaijenkij, and H. Zayar; Statistical analysis and data collection: K. Chaijenkij , H. Zayar, and K. Kaewkul

Conflict of Interests: We declare no conflict of interest. Ethical Approval: MU-CIRB 2019/268.0810.

Funding/Support: No funding or support was received for this study.

Informed Consent: According to the permission of Mahidol University Central Institutional Review Board, we explained our study procedure to the athletes and team medical staff. We provided the informed consent form, including a detailed explanation of the injury and illness surveillance procedure, to all athletes.

\section{References}

1. Bahr R, Engebretsen L. Handbook of sports medicine and science: sports injury prevention. 17. John Wiley \& Sons; 2011.
2. Rosen PV. Injuries, risk factors, consequences and injury perceptions in adolescent elite athletes. Flemingsberg, Sweden: Södertörn University; 2017.

3. Engebretsen L, Soligard T, Steffen K, Alonso JM, Aubry M, Budgett R, et al. Sports injuries and illnesses during the London Summer Olympic Games 2012. Br J Sports Med. 2013;47(7):407-14. doi: 10.1136/bjsports2013-092380. [PubMed: 23515712].

4. Soligard T, Steffen K, Palmer D, Alonso JM, Bahr R, Lopes AD, et al. Sports injury and illness incidence in the Rio de Janeiro 2016 Olympic Summer Games: A prospective study of 11274 athletes from 207 countries. Br J Sports Med. 2017;51(17):1265-71. doi: 10.1136/bjsports-2017097956. [PubMed: 28756389].

5. Engebretsen L, Bahr R. Why is Injury Prevention in Sports Important? Sports Injury Prevention. Hoboken, New Jersey: Wiley-Blackwell; 2009. doi: $10.1002 / 9781444303612 . c h 1$.

6. Junge A, Engebretsen L, Alonso JM, Renstrom P, Mountjoy M, Aubry $M$, et al. Injury surveillance in multi-sport events: the International Olympic Committee approach. BrJ Sports Med. 2008;42(6):413-21. doi: 10.1136/bjsm.2008.046631. [PubMed: 18390916].

7. Finch C. A new framework for research leading to sports injury prevention. J Sci Med Sport. 2006;9(1-2):3-9. doi: 10.1016/j.jsams.2006.02.009. [PubMed: 16616614].

8. Steffen K, Moseid CH, Engebretsen L, Soberg PK, Amundsen O, Holm $\mathrm{K}$, et al. Sports injuries and illnesses in the Lillehammer 2016 Youth Olympic Winter Games. Br J Sports Med. 2017;51(1):29-35. doi: 10.1136/bjsports-2016-096977. [PubMed: 27884864].

9. van Mechelen W, Hlobil H, Kemper HC. Incidence, severity, aetiology and prevention of sports injuries. A review of concepts. Sports Med. 1992;14(2):82-99. doi: 10.2165/00007256-199214020-00002. [PubMed: 1509229].

10. Palmer-Green D, Elliott N. Sports injury and illness epidemiology: Great Britain Olympic Team (TeamGB) surveillance during the Sochi 2014 Winter Olympic Games. Br J Sports Med. 2015;49(1):25-9. doi: 10.1136/bjsports-2014-094206. [PubMed: 25425714]. [PubMed Central: PMC4316851].

11. Nabhan D, Walden T, Street J, Linden H, Moreau B. Sports injury and illness epidemiology during the 2014 Youth Olympic Games: United States Olympic Team Surveillance. Br J Sports Med. 2016;50(11):688-93. doi: 10.1136/bjsports-2015-095835. [PubMed: 27098886].

12. Junge A, Engebretsen L, Mountjoy ML, Alonso JM, Renstrom PA, Aubry MJ, et al. Sports injuries during the Summer Olympic Games 2008. Am J Sports Med. 2009;37(11):2165-72. doi: 10.1177/0363546509339357. [PubMed: 19783812].

13. International Olympic Committee. London 2012 Olympic Summer Games Injury and Illness Surveillance Study. International Olympic Committee; 2014.

14. Ruedl G, Schobersberger W, Pocecco E, Blank C, Engebretsen L, Soligard $\mathrm{T}$, et al. Sport injuries and illnesses during the first Winter Youth Olympic Games 2012 in Innsbruck, Austria. Br J Sports Med. 2012;46(15):1030-7. doi: 10.1136/bjsports-2012-091534. [PubMed: 23148325].

15. Bahr R, Krosshaug T. Understanding injury mechanisms: a key component of preventing injuries in sport. BrJSports Med.2005;39(6):3249. doi: 10.1136/bjsm.2005.018341. [PubMed: 15911600]. [PubMed Central: PMC1725226].

16. Fernández AM, García NR, Gutiérrez G, Sanchez-Muñoz E, Munarriz CT. Lower Limb Injuries in Sport. Int J Phys Med Rehabil. 2020;8(5).

17. Hamid AM, Puji A, Salleh ZAIDI, Jamalullail Z, Hussein KH. Patterns of injuries and illness among Malaysian athletes during the XVII Asian games 2014. Sains Malays. 2016;45(10):1531-6.

18. McBain K, Shrier I, Shultz R, Meeuwisse WH, Klugl M, Garza D, et al. Prevention of sport injury II: a systematic review of clinical science research. BrJ Sports Med. 2012;46(3):174-9. doi: 10.1136/bjsm.2010.081182. [PubMed: 21471144]. 
19. Clarsen B, Myklebust G, Bahr R. Development and validation of a new method for the registration of overuse injuries in sports injury epidemiology: the Oslo Sports Trauma Research Centre (OSTRC) overuse injury questionnaire. BrJ Sports Med. 2013;47(8):495-502. doi: 10.1136/bjsports-2012-091524. [PubMed: 23038786].

20. Nieman DC. Risk of upper respiratory tract infection in athletes: an epidemiologic and immunologic perspective. $J$ Athl Train. 1997;32(4):344.

21. Luke A, d'Hemecourt P. Prevention of infectious diseases in athletes. Clin Sports Med. 2007;26(3):321-44. doi: 10.1016/j.csm.2007.04.006. [PubMed: 17826187]. [PubMed Central: PMC7131838]. 